\title{
Biomechanical Analysis of the Cervical Spine Following Disc Degeneration, Disc Fusion, and Disc Replacement: A Finite Element Study
}

\author{
ANUP A. GANDHI, PhD, ${ }^{1,2}$ NICOLE M. GROSLAND, PhD ${ }^{1-3}$ NICOLE A. KALLEMEYN, PhD, ${ }^{1,2}$ \\ SWATHI KODE, PhD, ${ }^{1,2}$ DOUGLAS C. FREDERICKS, BS, ${ }^{3}$ JOSEPH D. SMUCKER, MD, ${ }^{3}$ \\ ${ }^{1}$ Department of Biomedical Engineering, ${ }^{2}$ Center for Computer Aided Design, and ${ }^{3}$ Department of Orthopaedics and Rehabilitation, University of Iowa Hospitals \\ and Clinics, The University of Iowa, Iowa City, Iowa
}

\begin{abstract}
Background: Discectomy and fusion is considered the "gold standard" treatment for clinical manifestations of degenerative disc disease in the cervical spine. However, clinical and biomechanical studies suggest that fusion may lead to adjacent-segment disease. Cervical disc arthroplasty preserves the motion at the operated level and may potentially decrease the occurrence of adjacent segment degeneration. The purpose of this study was to investigate the effect of disc generation, fusion, and disc replacement on the motion, disc stresses, and facet forces on the cervical spine by using the finite element method.

Methods: A validated, intact, 3-dimensional finite element model of the cervical spine (C2-T1) was modified to simulate single-level (C5-C6) and 2-level (C5-C7) degeneration. The single-level degenerative model was modified to simulate both single-level fusion and arthroplasty (total disc replacement [TDR]) using the Bryan and Prestige LP discs. The 2-level degenerative model was modified to simulate a 2-level fusion, 2-level arthroplasty, and single-level disc replacement adjacent to single-level fusion (hybrid). The intact models were loaded by applying a moment of $\pm 2 \mathrm{Nm}$ in flexion-extension, lateral bending, and axial rotation. The motion in each direction was noted and the other modified models were loaded by increasing the moment until the primary C2-T1 motion matched that of the intact (healthy) C2T1 motion.

Results: Both Bryan and Prestige discs preserved motion at the implanted level and maintained normal motions at the adjacent nonoperative levels. A fusion resulted in a decrease in motion at the fused level and an increase in motion at the unfused levels. In the hybrid construct, the TDR (both) preserved motion adjacent to the fusion, thus reducing the demand on the other levels. The disc stresses followed the same trends as motion. Facet forces increased considerably at the index level following a TDR.

Conclusion: The Bryan and Prestige LP TDRs both preserved motion at the implanted level and maintained normal motion and disc stresses at the adjacent levels. The motion patterns of the spine with a TDR more closely resembled that of the intact spine than those of the degenerative or fused models.
\end{abstract}

Total Disc Replacement

Keywords: TDR, arthroplasty, cervical spine, biomechanics, fusion, finite element analysis, disc replacement adjacent to fusion, Bryan disc, Prestige LP disc, adjacent segment

\section{INTRODUCTION}

Anterior cervical discectomy and fusion has long been the standard treatment for disc-related problems. This technique has proven to be effective for pain relief and has allowed early return to function. However, fusion is known to increase the biomechanical stress on adjacent cervical segments, especially in the lower cervical spine. ${ }^{1,2}$ Cervical disc arthroplasty (total disc replacement [TDR]) achieves decompression of the neural elements similar to fusion, but it preserves the motion at the operated level and may potentially decrease the occurrence of adjacent segment degeneration. ${ }^{2}$

In vitro and in vivo experiments give valuable data, but unfortunately, information regarding internal responses is more difficult and often impractical to obtain. Hence, a commonly used technique to study spinal biomechanics is the finite element (FE) method.

Finite element analysis is an essential part of modern engineering activities. With the rapid expansion of FE-based software capabilities, the number of applications of these techniques has also 


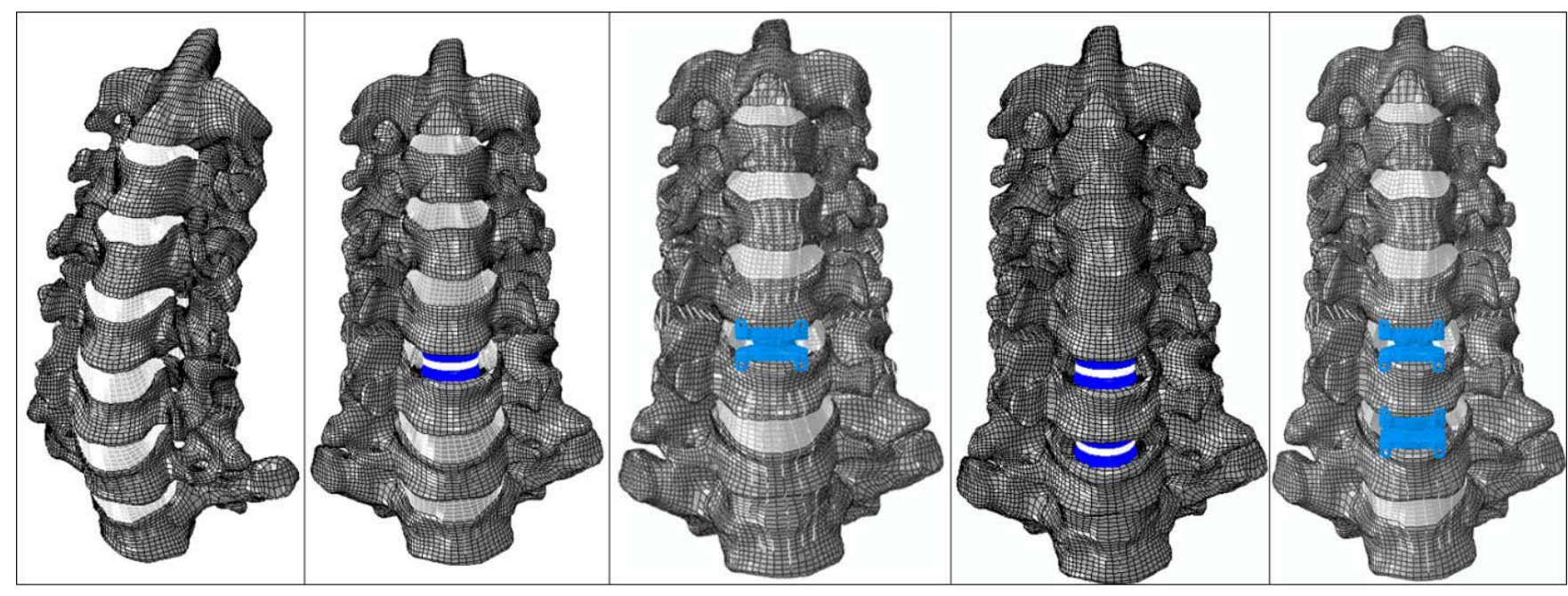

Figure 1. Three-dimensional finite element (FE) models, (left to right): intact, single-level Bryan, single-level prestige, 2-level Bryan, 2-level Prestige.

grown. The irregular geometry of vertebral bodies, complex nature of the disc, and facet contact between the adjacent vertebrae make modeling of the spine very complex. Hence, an enormous effort is required to generate accurate models that provide a true representation of spinal behavior. Advanced FE meshers are now able to accurately mesh complex structures such as the spine. Currently available commercial FE packages are capable of handling the complex geometry and nonlinearity found in the spine.

Finite element models are very useful in quantifying variables not directly measurable with experimental studies (eg, local stresses and strains). They are also powerful tools to assess the constraints in the functional spinal unit, specifically facet loading, stresses at the adjacent segments, and the contact forces at a prosthesis-bearing surface. Another important advantage of FE models is that, once validated, a number of parametric studies can be performed at minimal cost. The aim of this study was to study the effect of disc generation, fusion, and disc replacement on the motion, disc stresses, and facet forces of a cervical spine.

\section{MATERIALS AND METHODS}

\section{Intact Model}

An experimentally validated, 3-dimensional FE model of the cervical spine (C2-T1) was used for this study (Figure 1). ${ }^{3-7}$ The specimen-specific model was created from a computed tomography (CT) scan of a specimen tested experimentally. Details regarding the development and validation of the intact model have been summarized in previous publications. ${ }^{5,8}$ For the current investigation, this model was considered a "healthy" intact model. The model was subsequently altered to simulate states of single- and 2-level degeneration, as well as TDRs, fusion, and various combinations thereof, as detailed in the next section.

\section{Degenerative Models}

The aforementioned intact model was modified to simulate degenerative conditions by altering the material properties of the disc(s). ${ }^{9}$ Two degenerative states were considered: (1) degeneration at C5-C6 and (2) degeneration at C5-C6 and C6-C7. The adjacent levels were not modified. A moderately degenerated disc was simulated by removing the hydrostatic capabilities of the nucleus and by increasing the stiffness of the nucleus and annulus. ${ }^{3,4,9}$ Table 1 summarizes the hyperelastic Mooney-Rivlin material properties of the 3 regions of the annulus. The degenerated nucleus was assigned linear elastic material properties with an elastic modulus of $1.66 \mathrm{MPa}$ and a Poisson ratio of 0.4 . Although studies have demonstrated that disc

Table 1. Hyperelastic Mooney-Rivlin material properties for different regions of annulus ground substance in intact and degenerative models.

\begin{tabular}{|c|c|c|c|c|c|c|}
\hline & \multicolumn{2}{|c|}{ Anterior } & \multicolumn{2}{|c|}{ Posterior } & \multicolumn{2}{|c|}{ Lateral } \\
\hline & C1 & $\mathrm{C2}$ & C1 & $\mathrm{C2}$ & C1 & $\mathrm{C} 2$ \\
\hline \multicolumn{7}{|c|}{ Intact model } \\
\hline C5-C6 & 0.2 & 0.05 & 0.133 & 0.033 & 0.133 & 0.033 \\
\hline C6-C7 & 0.2 & 0.05 & 0.3 & 0.075 & 0.133 & 0.033 \\
\hline \multicolumn{7}{|c|}{ Degenerative model } \\
\hline C5-C6 & 1.05 & 0.2625 & 0.7 & 0.175 & 0.7 & 0.175 \\
\hline C6-C7 & 1.05 & 0.2625 & 1.5 & 0.375 & 0.7 & 0.175 \\
\hline
\end{tabular}




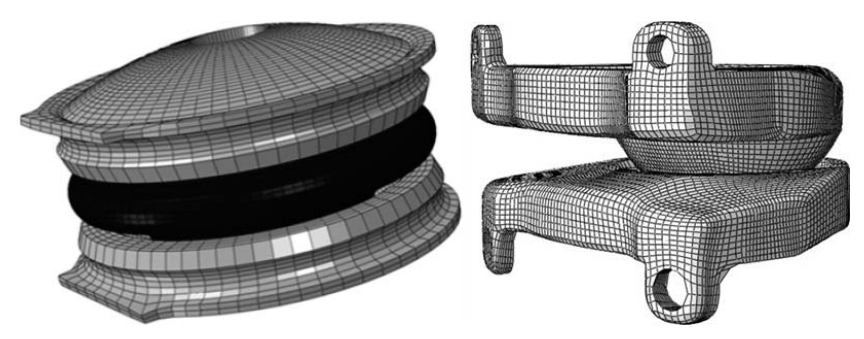

Figure 2. Three-dimensional finite element (FE) model of the Bryan cervical disc (left) and Prestige LP disc (right).

height and disc area also exhibit nominal changes as disc degeneration progresses, such changes were not incorporated in the current model for simplicity. ${ }^{10}$

\section{Fusion Models}

A single-level fusion model was developed by modifying the single-level degenerative model to simulate a fusion at the C5-C6 level. This was accomplished by converting the material properties of the annulus to that of bone $(\mathrm{E}=5 \mathrm{GPa}),{ }^{4,11}$ whereas the nucleus was replaced by a rigid body to simulate the presence of a metal cage. No additional instrumentation was included. Likewise, a 2-level fusion was simulated at the C5-C6 and C6-C7 levels via similar modifications.

\section{The Bryan Disc}

The Bryan cervical disc contains a polycarbonate polyurethane nucleus $(\mathrm{E}=30 \mathrm{MPa}, \mathrm{v}=0.45)$ that articulates superiorly and inferiorly with a titanium shell $(\mathrm{E}=110 \mathrm{GPa}, \mathrm{v}=0.3)$. A polyurethane sheath surrounds the nucleus and is attached to each shell using titanium wires. From a mechanical perspective, the sheath and wires are nonfunctional and hence were not included in the current model. A computer-aided design model of the disc was obtained with permission from Medtronic (Medtronic Sofamor Danek, Memphis, TN), enabling a representative FE mesh of each component to be generated (Figure 2). ${ }^{12}$ Four contact pairs were defined for each disc: 2 each for contact between the nucleus and the upper shell and between the nucleus and the lower shell (Figure 3). The contact between the shells and the nucleus was modeled as finite sliding with a coefficient of friction of $0.1 .^{13}$

\section{The Prestige LP Disc}

The Prestige LP is a titanium ceramic composite, comprising 2 articulating components (ball and trough). It is a low-profile arthroplasty device that

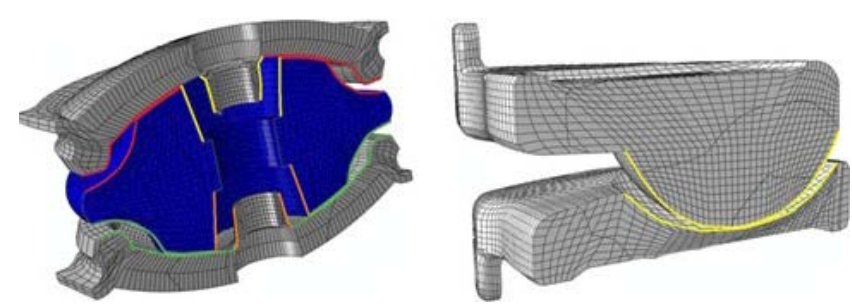

Figure 3. Section view of the Bryan (left) and Prestige LP (right) discs showing the different contact pairs.

achieves initial fixation via "rails" and long-term fixation via bony ongrowth as the result of a plasma spray.

A 3-dimensional FE mesh of the Prestige LP disc was created in IA-FEMesh using the surfaces provided by Medtronic (Medtronic Sofamor Danek). ${ }^{12}$ Both components of the disc were meshed with hexahedral elements (Figure 2). The rails and plasma coating were excluded from the mesh because the disc was assumed to be osseointegrated with the adjacent vertebral endplates. The 2 components of the disc were assigned an elastic modulus of $110 \mathrm{GPa}$ and Poisson ratio of 0.3 . The contact between the ball and trough was modeled as finite sliding with a coefficient of friction of 0.1 (Figure 3).

\section{Arthroplasty Models}

A single-level arthroplasty was simulated at the C5-C6 level by modifying the single-level degenerative model. A single-level TDR was performed for each device by mimicking the respective surgical technique. On the basis of CT measurements, an appropriately sized implant was selected $(8 \times 16-\mathrm{mm}$ Prestige LP disc and 16-mm Bryan disc) and meshed as described herein. To accommodate the implant, the elements representing the anterior longitudinal ligament, nucleus, and anterior/posterior annulus were removed. Care was taken to preserve as much of the lateral annulus, posterior, and uncinate processes as possible. The endplate cutting/milling operations were simulated using an in-house tool kit. ${ }^{14}$ Prior to incorporating the mesh of the artificial disc into the respective model, the C5-C6 disc space was distracted by $1.5 \mathrm{~mm}$ via FE analysis. The resulting stresses in the surrounding tissues as a result of the distraction were exported and assigned as initial conditions in the TDR model to simulate the initial compression on the implant. The superior and inferior components of each device were attached to the respective vertebral endplates to 
simulate complete osseointegration with the host bone. This was accomplished via the "TIED" contact capabilities available in ABAQUS Standard (ABAQUS Inc., Simulia Corp. Providence, Rhode Island).

A 2-level arthroplasty was simulated at the C5-C6 and C6-C7 levels by modifying the multilevel degenerative model (Figure 1). The aforementioned singlelevel modeling technique was extended to 2 levels. On the basis of CT measurements, the disc spaces of the adjacent levels were similar in height. Consequently, the same size disc was used in both models.

\section{Flexibility Test}

The healthy intact model was subjected to 2-Nm pure moments (at $\mathrm{C} 2$ ) in flexion-extension $( \pm \mathrm{MX})$, right-left lateral bending ( $\pm \mathrm{MZ})$, and right-left axial rotation $( \pm \mathrm{MY})$, whereas the inferior nodes of vertebra $\mathrm{T} 1$ were fixed in all directions. Thereafter, each of the other models was loaded in flexionextension, lateral bending, and axial rotation by increasing the moment until the primary C2-T1 motion matched that of the healthy C2-T1 model (Hybrid Control). ABAQUS (version 6.9) was used to perform all the FE analyses. The ranges of motion at each level, stresses in the discs, facet forces, and peak moments were recorded for analysis.

\section{RESULTS}

\section{Range of Motion}

The predicted ranges of motion of the $3 \mathrm{FE}$ models (intact, single-level degeneration at C5-C6 and 2-level degeneration at $\mathrm{C} 5-\mathrm{C} 6$ and $\mathrm{C} 6-\mathrm{C} 7)$ in the 6 loading directions are shown in Figure 4. The C5C6 degenerative model predicted a decrease in motion at the moderately degenerated level in all directions. A decrease in range of motion of approximately $32 \%$ was observed in flexion, approximately $33 \%$ in extension, approximately $45 \%$ in left/right lateral bending, and approximately $29 \%$ in left/right axial rotation at the C5-C6 level. The decrease in motion at the degenerated level was compensated by an increase in motion at the remaining levels, especially the adjacent levels, which showed an increase of approximately $10 \%$ in all directions. Similarly, in the 2-level degenerative model the C5-C6 and C6-C7 levels showed, respectively, a decrease of approximately $24 \%$ and approximately $42 \%$ in flexion, approximately $22 \%$ and approximately $42 \%$ in extension, approximate- ly $39 \%$ and approximately $49 \%$ in left/right lateral bending, and approximately $19 \%$ and approximately $40 \%$ in left/right axial rotation when compared with the intact/nondegenerative model. This decrease in motion once again resulted in an increase in motion at the remaining levels, especially the adjacent levels (Figure 4).

Compared with a single-level fusion, arthroplasty with both the Bryan and Prestige LP devices demonstrated an increase in motion at the implanted level and a decrease in motion at the adjacent levels (Figure 5). The TDR with Bryan showed an increase of approximately $15 \%$, approximately $21 \%$ and approximately $4 \%$ in flexion-extension, lateral bending, and axial rotation, respectively, whereas implantation of Prestige LP resulted in an increase in motion by approximately $24 \%$ in flexion-extension, approximately $13 \%$ in lateral bending, and approximately $10 \%$ in axial rotation. Fusion, on the other hand, resulted in a substantial decrease in motion (approximately 97\%) at the implanted level and a considerable increase in motion (approximately $16 \%$ ) at all other levels.

Figure 6 compares the percentage change in segmental range of motion with respect to the 2level degenerative model in flexion-extension, lateral bending, and axial rotation, after simulated surgical procedures of 2-level arthroplasty, single-level arthroplasty adjacent to single-level fusion (hybrid), and 2-level fusion. Similar to the single-level results, 2-level disc replacement showed an increase in motion at the operated levels that resulted in a decrease in motion at all other levels. This trend was consistent in all 6 directions. Segmental ranges of motion predicted for the both 2-level disc replacement models (Bryan and Prestige LP) were very similar to each other. Once again, 2-level fusion resulted in almost zero motion at the 2 fused levels. This drop in motion resulted in a substantial increase in motion across all unaltered levels, which was more than a single-level fusion.

The segmental motions predicted for the 2 hybrid models were very similar. In both hybrid models, the level with arthroplasty showed a large increase in motion. This increase was the most during flexionextension motion (more than $80 \%$ ). The increase in motion at the arthroplasty level resulted in a lesser increase in motion at the unaltered levels, suggesting that the arthroplasty bears the burden of the adjacent fusion while protecting the unaltered levels. As expected, the increase in motion at the unaltered 


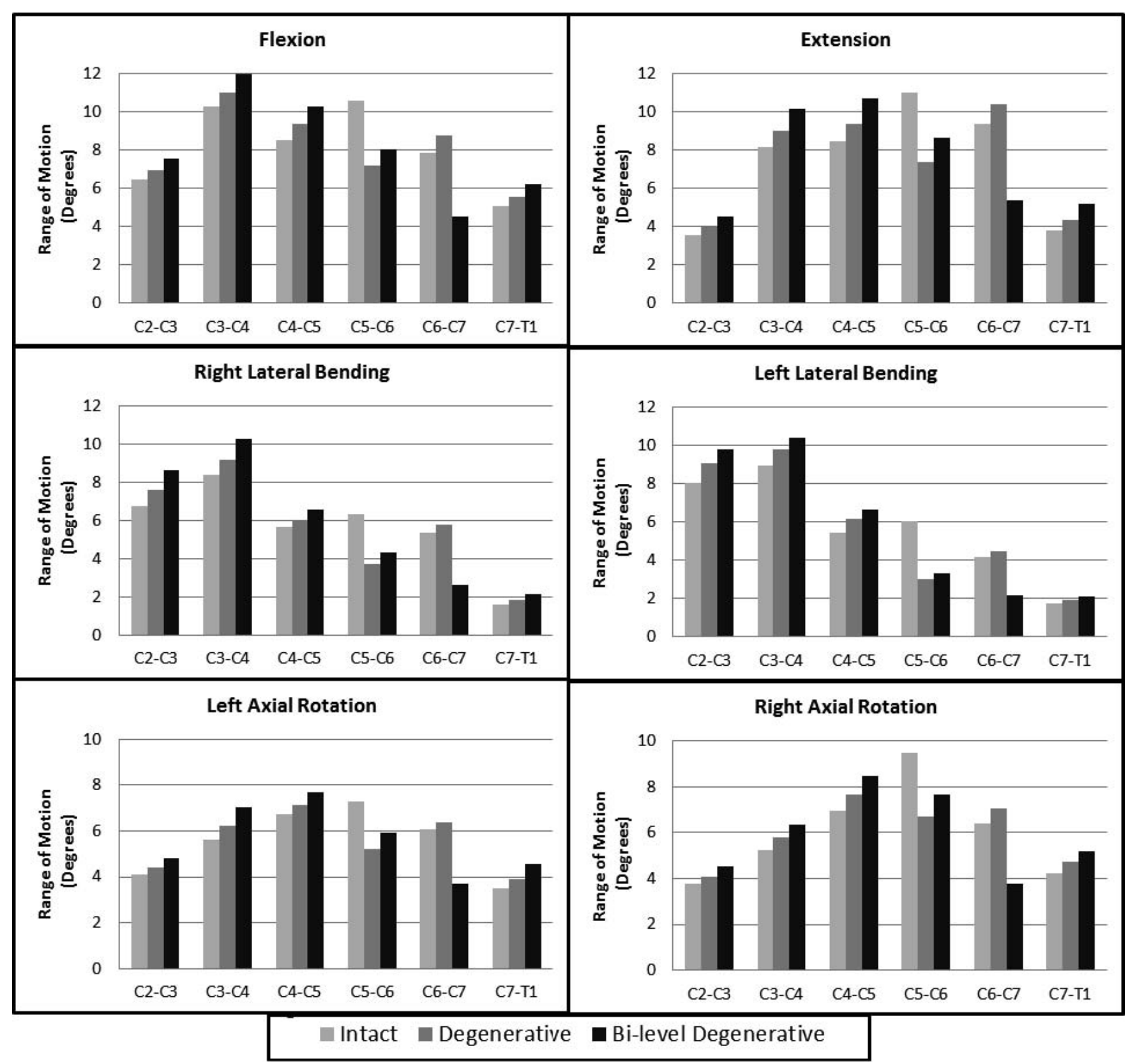

Figure 4. Comparison of range of motion in all 6 directions between intact (nondegenerative), single-level degenerative, and 2-level degenerative models.

levels in case of the 2-level fusion model was much more than the hybrid models. In all cases, a fusion resulted in almost zero motion at the fused level.

\section{Moments}

All the modified single-level models (ie, C5-C6 degenerative, C5-C6 fusion, and C5-C6 TDR with Bryan and Prestige) required moments greater than 2.0 $\mathrm{Nm}$ to obtain the same overall motion as the intact healthy model for each mode of loading (Table 2). The moment required for the fused model was the maximum (mean, $3.29 \mathrm{Nm}$ ), over $64 \%$ more
Table 2. Hybrid moments $(\mathrm{Nm})$ required in various single-level models to achieve overall range of motion equal to the intact model.

\begin{tabular}{lccccc}
\hline & Intact & Degenerative & Bryan & Prestige LP & Fusion \\
\hline Flexion & 2.0 & 2.3 & 2.3 & 2.3 & 3.0 \\
Extension & 2.0 & 2.5 & 2.3 & 2.2 & 3.5 \\
RLB & 2.0 & 2.4 & 2.3 & 2.2 & 3.0 \\
LLB & 2.0 & 2.5 & 2.5 & 2.5 & 2.9 \\
LAR & 2.0 & 2.3 & 2.5 & 2.4 & 3.4 \\
RAR & 2.0 & 2.5 & 2.4 & 2.3 & 3.9 \\
\hline
\end{tabular}

Abbreviations: LAR, left axial rotation; LLB, left lateral bending; RAR, right axial rotation; RLB, right lateral bending. 


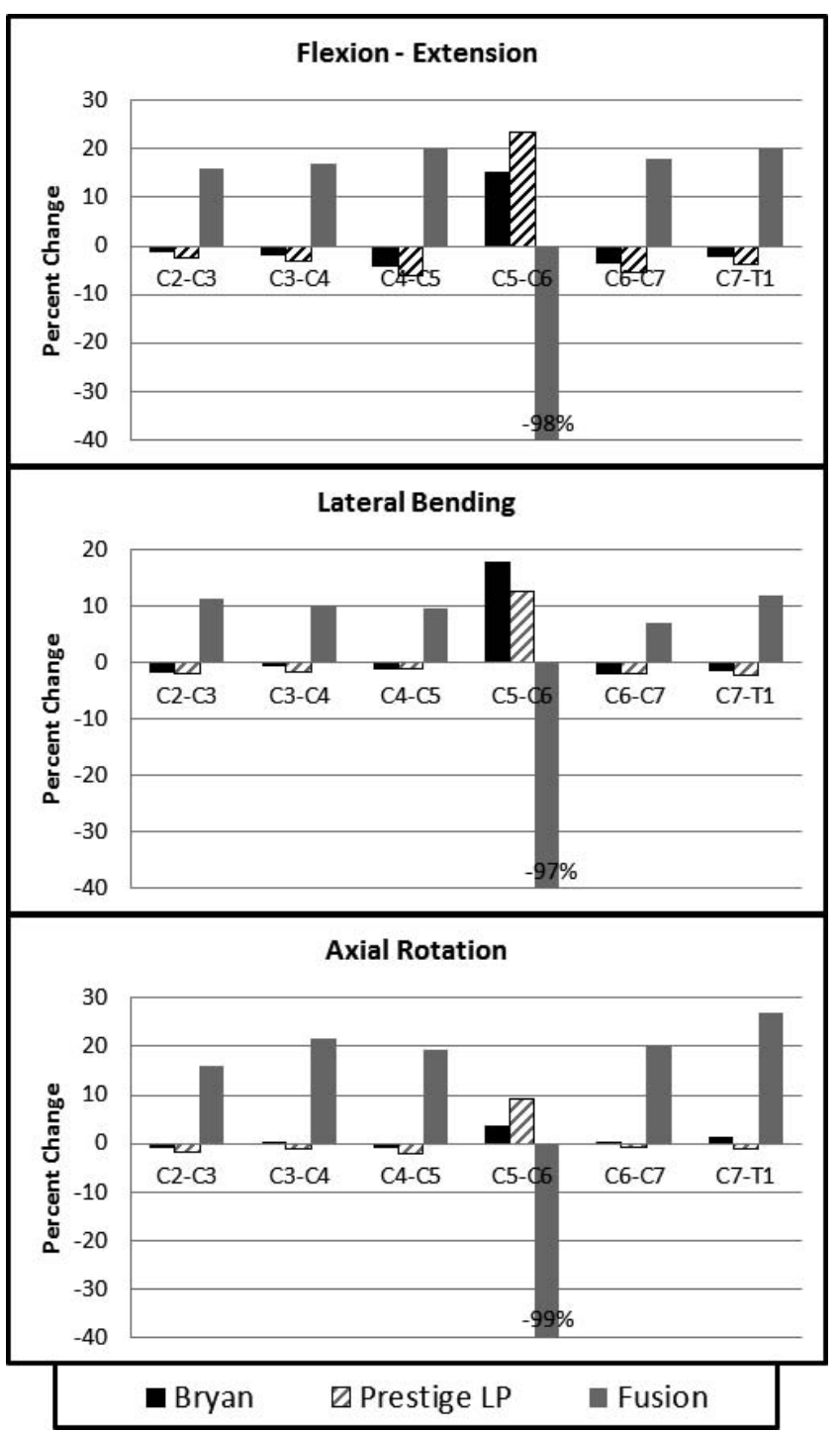

Figure 5. Percentage change in motion after fusion and arthroplasty with Bryan and Prestige LP with respect to motion of the degenerated model (C5-C6 level).

than the intact model. The degenerative model required an average moment of $2.4 \mathrm{Nm}$ to achieve the intact ROM. The TDR models needed a reduced moment (approximately $2.3 \mathrm{Nm}$ ) when compared with the degenerative model.

Table 3 lists the moments required to achieve the intact range of motion for 2-level TDR, hybrid, and

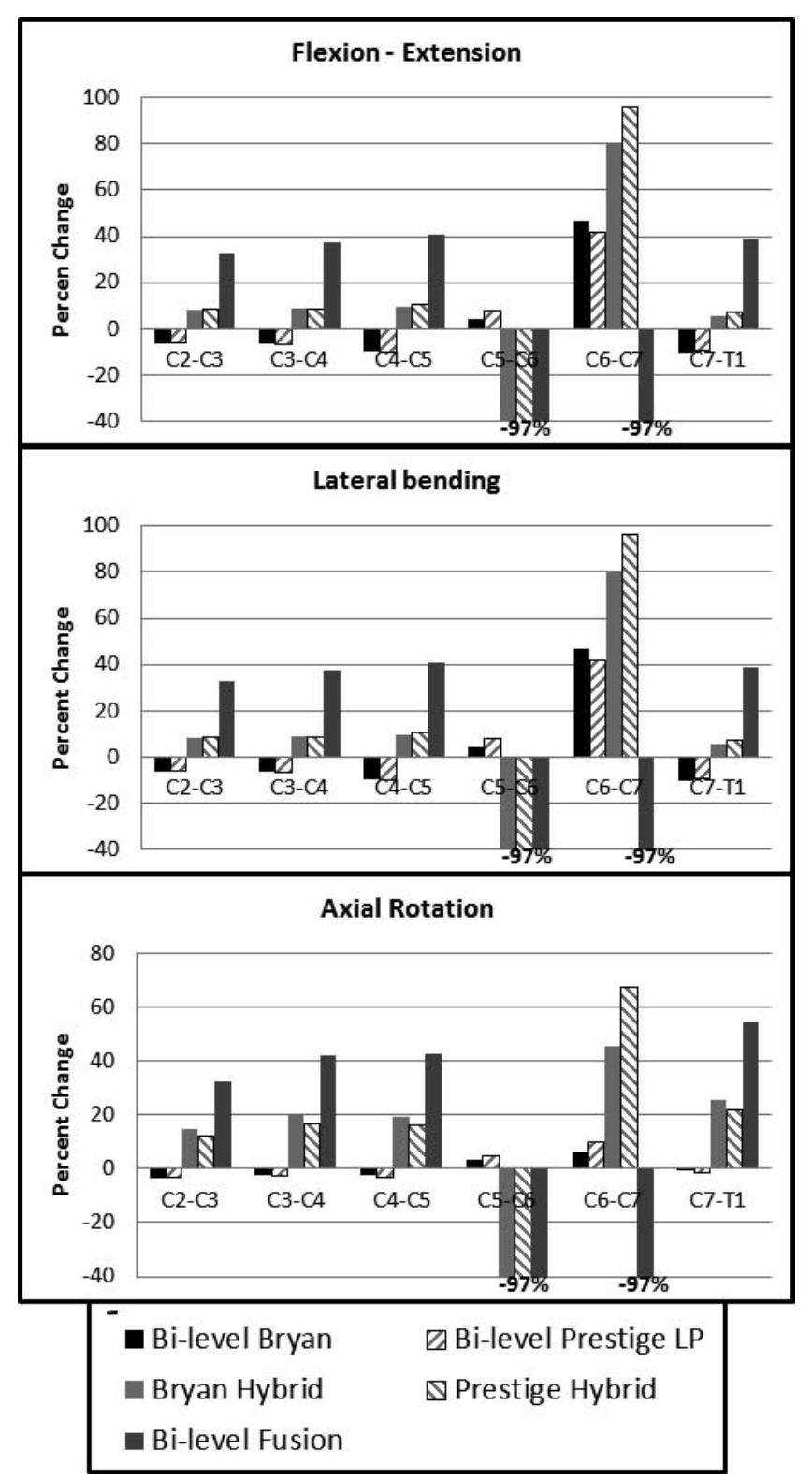

Figure 6. Percentage change in motion for 2-level TDR, hybrid, and 2-level fusion models.

2-level fusion models. As expected, the 2-level fusion model required the most moment ( $5 \mathrm{Nm}$ on average). Clearly, the 2-level fusion stiffened the spine significantly. The 2-level degenerative model required an average $50 \%$ more moment than the

Table 3. Hybrid moments $(\mathrm{Nm})$ required in various 2-level and hybrid models to achieve overall range of motion equal to the intact model.

\begin{tabular}{|c|c|c|c|c|c|c|c|}
\hline & Intact & 2-Level Degenerative & 2-Level Bryan & 2-Level Prestige LP & Bryan Hybrid & Prestige Hybrid & 2-Level Fusion \\
\hline Flexion & 2 & 2.72 & 2.62 & 2.52 & 3.36 & 3.20 & 4.25 \\
\hline Extension & 2 & 3.17 & 2.4 & 2.54 & 3.34 & 3.63 & 5.5 \\
\hline RLB & 2 & 3.02 & 2.60 & 2.54 & 3.50 & 3.47 & 4.36 \\
\hline LLB & 2 & 2.82 & 2.87 & 2.93 & 3.40 & 3.37 & 3.90 \\
\hline LAR & 2 & 2.90 & 3.0 & 2.94 & 4.10 & 3.87 & 5.5 \\
\hline RAR & 2 & 3.03 & 2.91 & 2.81 & 4.70 & 4.48 & 6.5 \\
\hline
\end{tabular}

Abbreviations: LAR, left axial rotation; LLB, left lateral bending; RAR, right axial rotation; RLB, right lateral bending. 


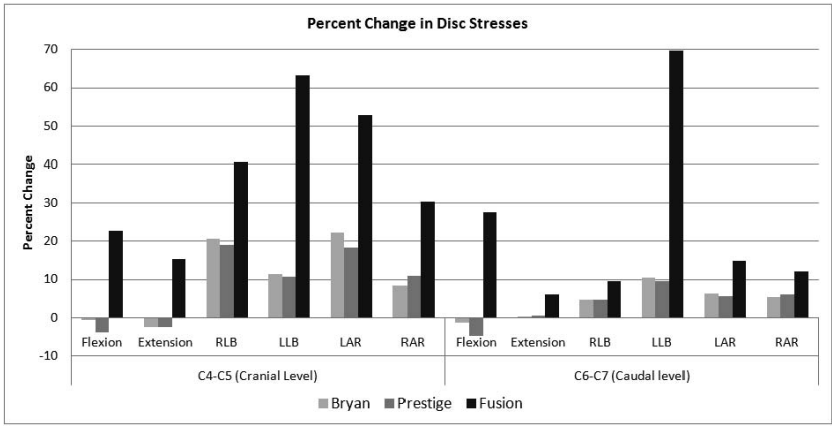

Figure 7. Percentage change in disc stresses after single-level disc replacement (Bryan and Prestige LP) and fusion in comparison to the degenerative model at the cranial and caudal levels.

healthy, nondegenerative model. Similar to the single-level results, the moments required for the TDR models were lower than for the 2-level degenerative model but higher than for the intact model. For hybrid models, the moments fell between the 2-level degenerative and 2-level fusion models.

\section{Adjacent-Level Disc Stresses}

Figure 7 depicts the percentage change in disc stresses at the level above and below the implanted level after single-level arthroplasty (Bryan and Prestige) and fusion. This percentage change is with respect to the single-level degenerative model. As expected, the disc stresses increased considerably in all 6 directions at both the cranial (approximately $37 \%$ ) and caudal (approximately 23\%) levels after fusion.

Figure 8 compares the percentage change in disc stresses at the level above and below the implanted level after 2-level arthroplasty (Bryan and Prestige), arthroplasty adjacent to fusion, and 2-level fusion. Similar to the trends observed with range of motion, the adjacent-level discs showed a large increase in stresses after 2-level fusion in all 6 directions. The 2-

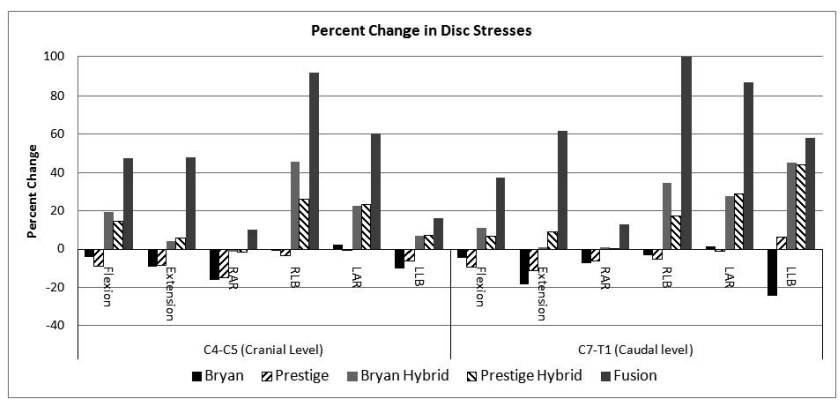

Figure 8. Percentage change in disc stresses after 2-level disc replacement (Bryan and Prestige LP), disc replacement adjacent to fusion, and 2-level fusion in comparison to the 2-level degenerative model at the cranial and caudal levels.
Table 4. Percentage change in facet contact forces at the altered and adjacent levels for intact and various single-level models under hybrid moments with respect to the intact model.

\begin{tabular}{lcrrr}
\hline & Degenerative & Bryan & Prestige LP & Fusion \\
\hline C4-C5 (cranial level) facet forces & & & \\
Extension & 30 & 10 & 12 & 102 \\
RLB & 38 & -15 & 19 & 88 \\
LLB & 27 & 31 & 38 & 65 \\
LAR & 13 & 26 & 6 & 71 \\
RAR & 37 & 42 & 42 & 153 \\
C5-C6 facet forces & & & & \\
Extension & -35 & 71 & 75 & $\ldots$ \\
RLB & -17 & 67 & 50 & $\ldots$ \\
LLB & -15 & 15 & -21 & $\ldots$ \\
LAR & 0 & 70 & 95 & $\ldots$ \\
RAR & 13 & 88 & 100 & $\ldots$ \\
C6-C7 (caudal level) facet forces & & & \\
Extension & 57 & 19 & 29 & 210 \\
RLB & 24 & -3 & 11 & 59 \\
LLB & 39 & 42 & 42 & 76 \\
LAR & 11 & 16 & 8 & 45 \\
RAR & 25 & 18 & 14 & 71 \\
\hline
\end{tabular}

Abbreviations: LAR, left axial rotation; LLB, left lateral bending; RAR, right axial rotation; RLB, right lateral bending.

level fusion model predicted an average of $45 \%$ and $60 \%$ higher stresses at the level above and below, respectively. Following a 2-level disc replacement, disc stresses at the adjacent levels dropped in almost all cases.

The increase in stresses due to a disc replacement with a fusion construct was considerably less when compared with the 2-level fusion model. In most cases, the stresses predicted for the 2 hybrid models were very similar.

\section{Facet Forces}

Facet contact forces for the altered level (C5-C6) and adjacent levels for intact, single-level degenerative, single-level Bryan and Prestige, and singlelevel fusion models are listed in Table 4. In comparison with the intact model, the degenerative model showed a decrease in contact force at the degenerated level and an increase in force at the adjacent levels. The TDR models, on the other hand, showed an increase in facet contact forces at the implanted level and a decrease at the adjacent levels in comparison to the degenerative model.

Facet contact forces for the altered levels (C5-C6 and C6-C7) and adjacent levels for intact, 2-level degenerative, 2-level Bryan and Prestige, hybrid Bryan and Prestige, and 2-level fusion models are listed in Table 5. The 2-level degenerative model showed a decrease in contact forces at the degenerated levels and an increase in force at the adjacent levels, in comparison to the intact model. The 2level TDR models, on the other hand, showed an 
Table 5. Percentage change in facet contact forces at the altered and adjacent levels for intact and various 2-level and hybrid models under hybrid moments with respect to the intact model.

\begin{tabular}{|c|c|c|c|c|c|c|}
\hline & 2-Level Degenerative & 2-Level Bryan & 2-Level Prestige LP & Bryan Hybrid & Prestige Hybrid & 2-Level Fusion \\
\hline \multicolumn{7}{|c|}{ C4-C5 (cranial level) facet forces } \\
\hline Extension & 80 & 28 & 36 & 90 & 106 & 248 \\
\hline RLB & 88 & 35 & 19 & 127 & 119 & 208 \\
\hline LLB & 54 & 50 & 54 & 92 & 85 & 146 \\
\hline LAR & 45 & 55 & 42 & 90 & 87 & 171 \\
\hline RAR & 68 & 95 & 116 & 268 & 242 & 421 \\
\hline \multicolumn{7}{|c|}{ C5-C6 (modified level-1) facet forces } \\
\hline Extension & -19 & 92 & 63 & $\ldots$ & $\ldots$ & $\ldots$ \\
\hline RLB & -8 & 75 & 92 & $\ldots$ & $\ldots$ & $\ldots$ \\
\hline LLB & -24 & 38 & 0 & $\ldots$ & $\ldots$ & $\ldots$ \\
\hline LAR & -5 & 160 & 110 & $\ldots$ & $\ldots$ & $\ldots$ \\
\hline RAR & -19 & 150 & 31 & $\ldots$ & $\ldots$ & $\ldots$ \\
\hline \multicolumn{7}{|c|}{ C6-C7 (modified level-2) facet forces } \\
\hline Extension & -19 & 143 & 100 & 219 & 195 & $\ldots$ \\
\hline RLB & -30 & 22 & -16 & 70 & 59 & $\ldots$ \\
\hline LLB & -39 & 42 & 42 & 58 & 64 & $\ldots$ \\
\hline LAR & -16 & 74 & 92 & 100 & 116 & $\ldots$ \\
\hline RAR & -21 & 21 & 50 & 96 & 111 & $\ldots$ \\
\hline \multicolumn{7}{|c|}{ C7-T1 (caudal level) facet forces } \\
\hline Extension & 90 & 34 & 31 & 110 & 117 & 283 \\
\hline RLB & 51 & 22 & -13 & 67 & 67 & 107 \\
\hline LLB & 43 & 24 & 30 & 76 & 72 & 102 \\
\hline LAR & 41 & 10 & 34 & 83 & 86 & 166 \\
\hline RAR & 67 & 33 & 40 & 193 & 167 & 353 \\
\hline
\end{tabular}

Abbreviations: LAR, left axial rotation; LLB, left lateral bending; RAR, right axial rotation; RLB, right lateral bending.

increase in facet contact forces at the implanted levels and a decrease at the adjacent levels in comparison to the degenerative model.

The facet forces at the C5-C6 level for both the hybrid models were zero due to fusion. At the C6C7 level (Bryan and Prestige LP), the facet forces were considerably higher in comparison to both intact and 2-level degenerative models. At the adjacent levels, however, the forces were between the 2-level fusion and 2-level degenerative models.

The increase in contact forces at the adjacent levels was largest in the case of 2-level fusion. Because the facets did not come into contact at the fused levels, all forces at these levels were zero.

\section{DISCUSSION}

The aim of this study was to compare biomechanics of the cervical spine following a combination of arthroplasty and fusion surgeries using FE analysis. A previously validated C2-T1 FE model of spine was used in this study. ${ }^{6,15}$ This model was validated with specimen-specific experimental data. As with most other FE analysis studies, this study has the general limitation where the effect of muscles on the stability of spine is not considered. Modeling a complex structure such the spine is very challenging. Certain assumptions are necessary to reduce the complexity without compromising the outcomes. As with most other FE analysis studies, this study has the general limitation where the effect of muscles on the stability of spine is ignored. Some studies apply a compressive load to mimic the weight of the head on the cervical spine. However, no compressive load was applied in this study in order to maintain consistent loading conditions between experimental ${ }^{24}$ and computational studies.

There have been very few studies that look at the effect of degeneration on the biomechanics of the cervical spine. Kumaresan et al ${ }^{16}$ used a C4-C6 FE model to simulate disc degeneration at the C5-C6 level. However, this study was more focused on the contribution of disc degeneration to osteophyte formation than the change in biomechanics due to disc degeneration. Thus, the degenerated model was not validated and was based on the work of Kumaresan et al. ${ }^{16}$ The results of this study indicated that the overall stiffness increased with the severity of disc degeneration.

Two degenerative models were created in this study, a single-level degenerative model at the C5C6 level and a 2-level degenerative model at the C5C6 and C6-C7 levels. In both cases, degeneration resulted in stiffening of the degenerated levels and, in turn, the entire model. As a result of this stiffness, the facet forces at the level decreased, whereas the motion, facet forces, and disc stresses at the adjacent levels increased. 
Several experimental and limited number of FE studies have been performed to study the effect of arthroplasty on the biomechanics of the cervical spine. Finite element studies by Galbusera et al, ${ }^{13,17}$ Faizan et $a l^{18}$ and Womack et $\mathrm{al}^{19}$ have confirmed that cervical arthroplasty devices preserve motion in a manner that is biomechanically superior to fusion. However, all of these studies modified the intact model to simulate a disc replacement surgery. Given that a disc replacement is typically performed to alleviate pain and other complications due to disc degeneration, we decided to use a degenerative model.

There are significant differences between the design of Prestige LP and Bryan discs. Prestige LP has an all-metal ball in a trough design, as opposed to Bryan, which has a polyurethane core sandwiched between titanium plates. In spite of the differences in the design, the overall range of motion at the implanted levels did not vary much between the 2 implants. It is possible that with the differences in design, the discs move differently (ie, different instantaneous centers of rotations). However, in this study we only looked at the overall range of motion.

With both artificial discs, the motion at the implanted level increased and the motion at the nonoperative levels decreased. In both single and 2level TDR models, the largest increase in motion was during flexion-extension. In most cases, the reduction in motion at the adjacent levels was less than 10\%. A fusion resulted in complete loss of motion at the fused level (an ideal clinical result) and a substantial increase in motion at the adjacent levels. In the case of a single-level fusion, the motion at the unfused levels increased by approximately $16 \%$, whereas for the 2-level fusion, the motion at the unfused levels increased by approximately $35 \%$. In the case of the hybrid models, however, the increase in motion at the nonoperative levels was just $12 \%$. This suggests that an arthroplasty procedure may be preferable over a fusion adjacent to a preexisting fusion.

The resulting moments followed the motion trends. A TDR model required a hybrid moment less than the corresponding degenerative model. A fused model required the greatest moment, especially the 2-level fusion, where the moment required was more than 2 times the intact model. The hybrid models fell between the 2-level TDR and the 2-level fusion models, supplementing the theory that an arthroplasty is a better alternative to a second fusion.

Previous studies have had inconsistent results to the effect of arthroplasty on facet forces. Some studies have shown no change in facet forces after arthroplasty, whereas others have demonstrated a significant increase in facet forces at the implanted level. Chang et $\mathrm{al}^{20}$ reported that following an arthroplasty, the facet loads increased at the index level in all directions with maximum increase during extension motion. This suggests that the facets may bear an increased burden of constraint as the result of either alteration of the functional spinal unit via arthroplasty and/or intrinsic characteristics of the device itself with respect to constraint. Metzger et $\mathrm{al}^{21}$ also conducted in vitro studies to investigate the changes in the facet load profile with the variation in the device positioning in the disc space. The authors reported that facet forces were sensitive to the device placement location and thereby indicated that improper positioning could potentially lead to higher facet loads following TDR. Contrary to these results, a similar study conducted by Steiber et $\mathrm{al}^{22}$ using ovine spines reported no significant increase in the facet loading after disc replacement. A computational study by Faizan et $\mathrm{al}^{18}$ which included a C3-C7 human FE model also concluded that under hybrid loading conditions TDR maintains facet loads similar to the intact values in most cases.

In this study, the facet forces at the implanted level increased considerably after a TDR. This could be attributed to disc placement. Although care was taken during implant placement and analysis, the FE models have some limitations that might have influenced the results of the study. The FE model results are strong functions of the inputs such as material properties, loading conditions, and implant locations. The cervical biomechanics is affected by alteration in the location of the implant in the disc space. For example, by shifting the implant in the anterior, posterior, or lateral directions or by changing the orientation of the implant in the disc space, the resulting biomechanics might be influenced as predicted by studies in both lumbar and cervical spine. ${ }^{18,23}$ More investigation will need to be undertaken in an effort to achieve understanding of disc positioning and functioning spinal unit constraint.

\section{CONCLUSION}

This study highlighted that cervical disc replacement with both Bryan and Prestige LP discs not only preserved the motion at the operated level but also maintained the normal motion at the adjacent levels. Under hybrid loading, the motion pattern of the spine with a TDR was closer to the intact motion pattern in 
comparison to the degenerative or fusion models. In the circumstance of an existing fusion, this study shows that a disc replacement is a better biomechanical alternative to an adjacent-level fusion.

\section{REFERENCES}

1. DiAngelo DJ, Roberston JT, Metcalf NH, McVay BJ, Davis RC. Biomechanical testing of an artificial cervical joint and an anterior cervical plate. J Spinal Disord Tech. Aug 2003;16(4);314-323.

2. Dmitriev AE, Cunningham BW, Hu N, Sell G, Vigna F, McAfee PC Adjacent level intradiscal pressure and segmental kinematics following a cervical total disc arthroplasty: an in vitro human cadaveric model. Spine (Phila Pa 1976). May 2005:30(10);1165-1172.

3. Gandhi AA. Biomechanical Analysis of the Cervical Spine Following Total Disc Arthroplasty: an Experimental and Finite Element Investigation [dissertation]. Iowa City, IA: University of Iowa; 2012.

4. Anup G, Swathi K, Douglas F, Joseph S, Nicole G. Biomechanical comparison of cervical disc replacement and fusion using bi-level and hybrid constructs: a finite element study. International Society for Advancement of Spinal Surgery, Barcelona, Spain, March 20-23, 2012.

5. Kallemeyn N, Gandhi A, Kode S, Shivanna K, Smucker J, Grosland N. Validation of a C2-C7 cervical spine finite element model using specimen-specific flexibility data. Med Eng Phys. Jun 2010;32(5):482-489.

6. Kode S, Kallemeyn NA, Smucker JD, Fredericks DC, Grosland NM. The effect of multi-level laminoplasty and laminectomy on the biomechanics of the cervical spine: a finite element study. Iowa Orthop J. 2014;34:150-157.

7. Kallemeyn NA, Shivanna KH, DeVries NA, et al. Advancements in spine FE mesh development: toward patientspecific models. In: Gefen A, ed. Patient-Specific Modeling in Tomorrow's Medicine. Berlin, Germany: Springer; 2012:75-101.

8. Kode S, Kallemeyn NA, Smucker JD, Fredericks DC, Grosland NM. The effect of multi-level laminoplasty and laminectomy on the biomechanics of the cervical spine: a finite element study. Iowa Orthop J. 2014;34:150-157.

9. Ruberté LM, Natarajan RN, Andersson GB. Influence of single-level lumbar degenerative disc disease on the behavior of the adjacent segments - a finite element model study. $J$ Biomech. 2009;42(3):341-348.

10. Natarajan RN, Williams JR, Andersson GB. Modeling changes in intervertebral disc mechanics with degeneration. $J$ Bone Joint Surg Am. Apr 2006;88(suppl 2):36-40.

11. Kallemeyn N, Smucker J, Fredericks D, Shivanna K, Grosland N. Single level fusion in a C27 cervical spine finite element model. In: 33rd Annual Meeting of the American Society of Biomechanics, State College, PA, August 26-29, 2009.

12. Grosland NM, Shivanna KH, Magnotta VA, et al. IAFEMesh: an open-source, interactive, multiblock approach to anatomic finite element model development. Comput Methods Programs Biomed. 2009;94(1):96-107.

13. Galbusera F, Bellini CM, Raimondi MT, Fornari M, Assietti R. Cervical spine biomechanics following implantation of a disc prosthesis. Med Eng Physics. 2008;30(9):1127-1133.

14. Tadepalli SC, Shivanna KH, Magnotta VA, Kallemeyn
NA, Grosland NM. Toward the development of virtual surgical tools to aid orthopaedic FE analyses. EURASIP J Adv Signal Process. 2010;2010(1):1902931.

15. Kallemeyn N, Gandhi A, Kode S, Shivanna K, Smucker J, Grosland N. Validation of a C2-C7 cervical spine finite element model using specimen-specific flexibility data. Med Eng Phys. 2010;32(5):482-489.

16. Kumaresan S, Yoganandan N, Pintar FA, Maiman DJ, Goel VK. Contribution of disc degeneration to osteophyte formation in the cervical spine: a biomechanical investigation. $J$ Orthop Res. 2001;19(5):977-984.

17. Galbusera F, Fantigrossi A, Raimondi M, Assietti R, Sassi M, Fornari M. Biomechanics of the C5-C6 spinal unit before and after placement of a disc prosthesis. Biomech Model Mechanobiol. 2006;5(4):253-261.

18. Faizan A, Goel VK, Biyani A, Garfin SR, Bono CM. Adjacent level effects of bi level disc replacement, bi level fusion and disc replacement plus fusion in cervical spine-a finite element based study. Clin Biomech. 2012;27(3):226-233.

19. Womack W, Leahy PD, Patel VV, Puttlitz CM. Finite element modeling of kinematic and load transmission alterations due to cervical intervertebral disc replacement. Spine. 2011;36(17):E1126-E1133.

20. Chang U-K, Kim DH, Lee MC, Willenberg R, Kim S-H, Lim J. Changes in adjacent-level disc pressure and facet joint force after cervical arthroplasty compared with cervical discectomy and fusion. J Neurosurg Spine. 7(1), pp.33-39.

21. Metzger M, Buckley J, O’Reilly O, Lotz J. Facet forces sensitive to total disc replacement device position. Paper presented at: Orthopedics Research Society; 2008; San Francisco, California.

22. Stieber JR, Quirno M, Kang M, Valdevit A, Errico TJ. The facet joint loading profile of a cervical intervertebral disc replacement incorporating a novel saddle-shaped articulation. $J$ Spinal Disord Tech. 2011;24(7):432-436.

23. Dooris AP, Goel VK, Grosland NM, Gilbertson LG, Wilder DG. Load-sharing between anterior and posterior elements in a lumbar motion segment implanted with an artificial disc. Spine. 2001;26(6):E122-E129.

Disclosures and COI: The authors received no funding for this study and report no conflicts of interest. The implant CAD models used in this study were provided by Medtronic Sofamor Danek USA Inc.

Corresponding Author: Nicole Grosland, $\mathrm{PhD}$, Department of Biomedical Engineering, The University of Iowa, Iowa City, IA 52242. Phone: (319) 335-6425; Fax: (319) 335-5631; Email: nicole-grosland@uiowa.edu.

Published 31 December 2019

This manuscript is generously published free of charge by ISASS, the International Society for the Advancement of Spine Surgery. Copyright (C) 2019 ISASS. To see more or order reprints or permissions, see http://ijssurgery.com. 